Editors' Note: Drs. Shubhakaran and Khichar offer their insights into dementia in India in response to "Dementia in China: Current status." Authors Wang et al. respond. In reference to "Electronic media in neurology education: Progress, promise, and pitfalls," Dr. Walsh broadens the discussion on e-learning resources. Dr. Finelli discusses the role of information technology in diagnosis.

-Megan Alcauskas, MD, and Robert C. Griggs, MD

\section{DEMENTIA IN CHINA: CURRENT STATUS}

Khichar Purnaram Shubhakaran, Rekha Jakhar

Khichar, Jodhpur, India: We read the article by

Liu et al. ${ }^{1}$ with interest. As the aging population grows, good geriatric medical services all over the world are needed. Developed countries are close to fulfilling these requirements, but problems exist in developing and third world countries like India, where adequate infrastructure and data are lacking. There are regional differences in dementia prevalence $(0.8 \%-4.1 \%)$, which could be due to ethnic diversity, education level, diet, social customs/rituals, and medical infrastructure. ${ }^{2}$ The incidence of degenerative dementia in India is far less compared to the West, but stroke, infection, malnutrition, and alcohol contribute to most dementia. ${ }^{3}$ The use of curcumin — widely used in India — is considered protective for dementia, ${ }^{2}$ yet patients need more than is offered. There are provisions for free medicine and some imaging in many parts of India, but more complex investigation is costly, which adds to the existing problem. Medicines like donepezil, memantine, and rivastigmine also come at a price. The free drug distribution protocol needs to be upgraded.

\section{Author Response: Lu-ning Wang, Jia Liu, Ji-ping} Tan, Beijing, China: We thank Drs. Shubhakaran and Khichar for their comments related to dementia in India. China and India together account for 2 out of every 5 people in the world. With the population aging, geriatric neurologic diseases such as dementia and parkinsonism are becoming an enormous challenge for the national public health system. The rate of neurodegenerative dementia in China has been compared to the West by several nationwide epidemiologic investigations, with higher prevalence in rural areas compared to urban areas.
With potential neuroprotective effects, curcumin is also a complementary treatment for dementia in China. However, data confirming the effectiveness of this type of treatment are lacking. Meanwhile, traditional Chinese herbs such as gingko biloba and serrate clubmoss are also widely used as complementary treatments. The use of herbal therapy for dementia can be traced back thousands of years to ancient China, ${ }^{4}$ but large-scale, well-designed clinical trials are required to confirm their efficacy.

(C) 2014 American Academy of Neurology

1. Liu J, Wang L, Tan J. Dementia in China: current status. Neurology 2013;81:1077-1078.

2. Das SK, Pal S, Ghosal MK. Dementia: Indian perspective. Neurol India 2012;60:615-624.

3. Jha S, Patel R. Some observations on the spectrum of dementia. Neurol India 2004;52:312-314.

4. Liu J, Wang LN, Tian JZ. Recognition of dementia in ancient China. Neurobiol Aging 2012;33:2948.e11-2948.e13.

\section{OPINION \& SPECIAL ARTICLES: ELECTRONIC MEDIA IN NEUROLOGY EDUCATION: PROGRESS, PROMISE, AND PITFALLS}

Kieran Walsh, London: Lakhan et al. ${ }^{1}$ should be praised for their account of the role of electronic media in neurology education. They balanced the progress with the pitfalls, which is always both welcome and wise. However, the article does not quite do justice to the myriad types of e-learning resources that are available, the roles that they can play, and the speed of change in this area. In the past, it may have been possible to do a systematic review of the effectiveness of e-learning resources, yet this is no longer possible as an interactive multimedia resource will have a different impact vs a text-based resource. In the past, it may have been possible to say that e-learning can help with applied knowledge or problem-solving skills but will not help communication or procedural skills. However, the advent of Skype enabling synchronous communication and role play or an iPad's accelerometer that can tell learners to press harder or faster when practicing cardiopulmonary resuscitation are rapidly dispelling received truths about e-learning.

These truths have been short-lived and the pace of change continues afoot. We will have to run fast to keep up. 


\section{Neurology}

Dementia in China: Current status

Khichar Purnaram Shubhakaran, Lu-ning Wang, Rekha Jakhar Khichar, et al. Neurology 2014;82;1291

DOI 10.1212/WNL.0000000000000233

\section{This information is current as of April 7, 2014}

\section{Updated Information \&} Services

References

Permissions \& Licensing

Reprints including high resolution figures, can be found at: http://n.neurology.org/content/82/14/1291.1.full

This article cites 4 articles, 1 of which you can access for free at: http://n.neurology.org/content/82/14/1291.1.full\#ref-list-1

Information about reproducing this article in parts (figures,tables) or in its entirety can be found online at:

http://www.neurology.org/about/about_the_journal\#permissions

Information about ordering reprints can be found online: http://n.neurology.org/subscribers/advertise

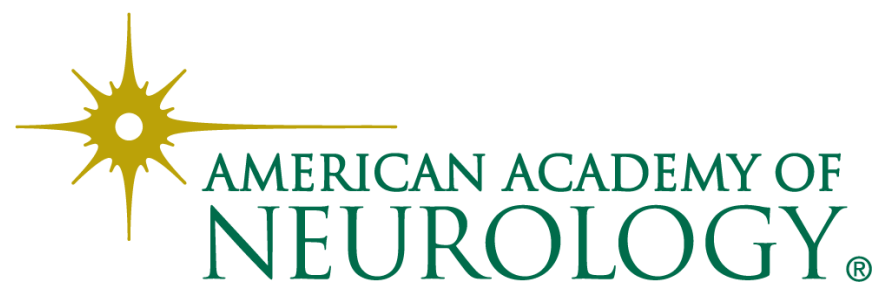

